\title{
ZASTOSOWANIE ZMODYFIKOWANEJ METODY POT Z MODELAMI ZMIENNOŚCI DO OCENY RYZYKA INWESTYCJI NA RYNKU KAPITAŁOWYM
}

\begin{abstract}
$\mathrm{Z}$ a r y s t r e ś c i. Celem artykułu jest prezentacja nowego podejścia mającego na celu połączenie modeli zmienności z metodą Peaks over Threshold (POT), wywodzącą się z teorii wartości ekstremalnych. Podejście to opiera się na możliwości szacowania ekstremów na podstawie metody POT, natomiast wartości średnich na podstawie modeli zmienności. W pracy zastosowano metodę POT dla stóp zwrotu indeksów rynków finansowych przefiltrowanych za pomocą modeli GARCH oraz SV, które porównano z wynikami otrzymanymi tylko za pomocą modeli GARCH i SV.

S ło w a k 1 u c z o w e: teoria wartości ekstremalnych, Peaks over Threshold, miary ryzyka.
\end{abstract}

\section{WSTĘP}

Dokładne szacowanie ryzyka jest kluczem do dobrego zarządzania ryzykiem. To proste zdanie wydaje się banałem, ale samo zagadnienie estymacji ryzyka inwestycji na rynku kapitałowym nie jest proste i od dawna bardzo często rozważane $\mathrm{w}$ literaturze przedmiotu. Obecna literatura w tym zakresie jest bardzo obszerna, a wyniki badań często są niejednoznaczne. Często przyczyną upadków instytucji finansowych było niewłaściwe zarządzanie ryzykiem rynkowym. W związku z takim stanem rzeczy wiele instytucji i osób zainteresowało się technikami ilościowymi pozwalającymi na oszacowanie możliwych strat. Ponieważ nie można całkowicie uniknąc ryzyka, należy poznać rządzące nim mechanizmy i nauczyć się nim zarządzać. W finansach fundamentalną zmienną jest stopa zwrotu inwestycji, która jest szacowana przez inwestora. Istniejące podejścia do modelowania rozkładu zysków/strat portfela instrumentów finansowych można schematycznie podzielić na trzy grupy: nieparametryczne metody symulacji historycznej, parametryczne metody oparte na modelach zmienności (rodzina modeli GARCH itp.) i w końcu metody oparte na teorii wartości 
ekstremalnych (EVT). W niniejszej pracy skupiono się na metodach opartych o modele zmienności i na metodzie Peaks over Threshold (POT) wywodzącej się z teorii wartości ekstremalnych (ang. Extreme Value Theory). Jednakże największą uwagę skupiono tutaj na nowej propozycji połączenia wyżej wymienionych metod.

\section{METODA POT I MODELE ZMIENNOŚCI}

Metoda Peaks over Threshold skupia uwagę na przekroczeniach powyżej zadanej wysokiej wartości progowej $u$. Szczegółowy opis metody POT można znaleźć w pracach: Embrechts, Klüppelberg, Mikosch (2003), lub Osińska, Fałdziński (2007). Tutaj w skrócie przedstawione zostanie podejście McNeila i Freya (2000), którzy połączyli modele zmienności i metodę POT. Na początek przyjmuje się, że $X_{t}$ jest szeregiem czasowym reprezentującym dzienne obserwacje stóp zwrotu instrumentu finansowego. Zakładamy, że dynamika procesu $X$ jest dana następująco:

$$
X_{t}=\mu_{t}+\sigma_{t} Z_{t},
$$

gdzie innowacje $Z_{t}$ są białym szumem z zerową średnią, jednostkową wariancją i dystrybuantą rozkładu brzegowego $F_{Z}(z)$. Zakładamy, że $\mu_{t}$ jest oczekiwanym zwrotem, a $\sigma_{t}$ jest zmiennością stóp zwrotu, gdzie obie są mierzalne $\mathrm{W}$ stosunku do zbioru informacji $\mathrm{F}_{t-1} \mathrm{~W}$ czasie $t-1$. Aby zastosować procedurę estymacji dla procesu (1), należy wybrać dynamiczny model warunkowej średniej i warunkowej wariancji. Wiele modeli zmienności zostało zaproponowanych w literaturze ekonometrycznej, od modeli ARCH/GARCH przez ich różnorodne modyfikacje i uogólnienia, aż do modeli SV. McNeil i Frey zdefiniowali proste jednodniowe formy miar ryzyka w stosunku do procesu (1) jako:

$$
\begin{aligned}
& \operatorname{VaR}_{q}^{t}=\mu_{t+1}+\sigma_{t+1} \operatorname{VaR}(Z)_{q} \\
& E S_{q}^{t}=\mu_{t+1}+\sigma_{t+1} E S(Z)_{q},
\end{aligned}
$$

gdzie $\operatorname{VaR}_{q}^{t}(Z)$ jest wartością zagrożoną procesu $Z_{t}$, a $E S_{q}^{t}(Z)$ jest odpowiadającym oczekiwanym niedoborem. Metoda przez nich zaproponowana zakłada minimalne założenia co do rozkładu innowacji i skupia się na modelowaniu ogona rozkładu używając teorii wartości ekstremalnych. Ogólnie można powiedzieć, że używają dwuetapowego podejścia, które może być przedstawione następująco:

1. Dopasowanie modelu z rodziny GARCH (ogólnie modelu zmienności) do szeregu stóp zwrotu. Estymuje się $\mu_{t+1}$ i $\sigma_{t+1}$ używając założonego modelu zmienności i oblicza się standaryzowane reszty modelu. Oznacza to, że model ten jest użyty do szacowania jednookresowych prognoz $\mu_{t+1}$ i $\sigma_{t+1}$. 
2. Używamy teorii wartości ekstremalnych, aby otrzymać wartości $\operatorname{VaR}(Z)_{q}$ i $E S(Z)_{q}$ za pomocą metody Peaks over Threshold na podstawie standaryzowanych reszt modelu z punktu 1.

Wartość zagrożona $\mathrm{w}$ teorii wartości ekstremalnych dla metody Peaks over Threshold jest równa:

$$
\operatorname{VaR}(\alpha)=u+\frac{\hat{\sigma}}{\hat{\gamma}}\left(\left(\frac{n}{N_{u}} \alpha\right)^{-\hat{\gamma}}-1\right),
$$

gdzie $\alpha$ jest poziomem istotności, $u$ jest wartością progowa, $\hat{\gamma}, \hat{\sigma}$ są parametrami uogólnionego rozkładu Pareto (GPD), $n$ jest liczbą obserwacji w szeregu, natomiast $N_{u}$ jest liczbą ekstremów. Z powodu wad wartości zagrożonej powstała alternatywna miara ryzyka, która nazywana jest oczekiwanym niedoborem (Expected Shortfall, ES), Artzner, Delbaen, Eber, Heath (1997), Artzner Delbaen, Eber, Heath (1999). Expected Shortfall dla metody Peaks over Threshold jest wyrażona następująco:

$$
E S(\alpha)=\frac{\operatorname{VaR}(\alpha)}{1-\hat{\gamma}}+\frac{\hat{\sigma}-\hat{\gamma} u}{1-\hat{\gamma}}
$$

W literaturze można spotkać porównania modeli szacujących VaR i ES, gdzie zastosowano teorię wartości ekstremalnych np. (Brooks, Clare, Dalle Molle, Persand, 2005; Harmantzis, Miao, Chien, 2006; Kuester, Mittnik, Paolella, 2006; Osińska, Fałdziński, 2007; Fałdziński, 2008). We wszystkich pracach stwierdzono, że EVT jest dobrą lub bardzo dobrą metodą szacowania miar ryzyka.

Z przedstawionych rezultatów empirycznych w wyżej wymienionych pracach wynika, że modele zmienności z zastosowaniem teorii wartości ekstremalnych dokładniej szacują oczekiwane wartości przyszłych stóp zwrotu zwłaszcza w przypadku wydarzeń o niespotykanej skali (ekstremów). W przeciwieństwie do modeli z EVT, standardowe modele zmienności lepiej dopasowują się do wartości średnich w finansowych szeregach czasowych. Dlatego też nowe podejście opiera się na możliwości takiego połączenia, aby ekstrema szacowane były na podstawie metody POT, natomiast wartości średnie na podstawie modeli zmienności. Połączenie to polega na próbie identyfikacji ekstremów w finansowych szeregach czasowych. Nowy podejście może zostać zapisane w następującej postaci:

$$
N-G A R C H-P O T= \begin{cases}G A R C H-P O T & \mu_{t+1}+\sigma_{t+1} \geq u_{t} \\ G A R C H & \mu_{t+1}+\sigma_{t+1}<u_{t}\end{cases}
$$

Ten nowy hybrydowy model zmienności i metody POT opiera się na prognozie warunkowej zmienności $\sigma_{t+1}$ i warunkowej średniej $\mu_{t+1}$, oraz na wartości pro- 
gowej $u_{t}$. Jeżeli suma prognoz $\mu_{t+1}$ i $\sigma_{t+1}$ jest większa od wartości progowej to stosujemy podejście McNeila i Freya, w przeciwnym wypadku mamy standardowy model GARCH. Wartość progowa $u_{t}$ może być ustalona $\mathrm{z}$ góry, bądź może być zmienna w czasie. Przełączanie zostało skonstruowane w taki sposób, aby identyfikowało czy prognoza stopy zwrotu szeregu czasowego jest wartością ekstremalną czy nie. Prognoza stóp zwrotu ma bardzo ważne znaczenie, ponieważ im dokładniejsza prognoza, co do przyszłej wartości szeregu czasowego, tym lepiej identyfikowane są ekstrema, co wiąże się z prawidłowym przełączaniem w podanej reprezentacji (6). Idea nowego podejścia w całej mierze polega na możliwości prognostycznej przyszłej wartości stopy zwrotu na podstawie danego modelu zmienności ( $\mathrm{w}$ tym przypadku jest to model GARCH).

\section{TESTOWANIE WSTECZNE}

Bardzo ważnym zagadnieniem w przypadku miar ryzyka jest konieczność sprawdzania poprawności ich estymacji i jednocześnie wyboru najdokładniejszej metody ich szacowania. Do testowania wstecznego użyto trzech testów dwumianowych (ang. binomial tests): test liczby przekroczeń $L R_{u c}$, test niezależności przekroczeń $L R_{\text {ind }} K$ (Haas, 2001), test niezależności przekroczeń $L R_{\text {ind }} C H$ (Christoffersen, 1998). Niestety przedstawione testy charakteryzują się słabą mocą, a w dodatku nie dają możliwości stworzenia rankingu modeli. Angelidis i Degiannakis (2006) przedstawili zmodyfikowaną funkcję straty Lopeza (1999):

$$
\begin{aligned}
& \Psi_{1, t+1}= \begin{cases}\left|y_{t+1}-E S_{t+1 \mid t}\right| & \text { jeżeli nastapi przekroczenie } \\
0 & \text { w przeciwnym przypadku }\end{cases} \\
& \Psi_{2, t+1}= \begin{cases}\left(y_{t+1}-E S_{t+1 \mid t}\right)^{2} & \text { jeżeli nastapi przekroczenie } \\
0 & \text { w przeciwnym przypadku }\end{cases}
\end{aligned}
$$

Aby ocenić, który model jest najlepszy, dla każdego oblicza się średni błąd absolutny (MAE) $M A E=\sum_{t=1}^{\tilde{T}} \Psi_{1, t} / \tilde{T}$, oraz średni błąd kwadratowy (MSE) $M S E=\sum_{t=1}^{\tilde{T}} \Psi_{2, t} / \tilde{T}$, gdzie $\tilde{T}$ jest liczbą wykonanych prognoz, a funkcja straty $(L F)$ jest sumą tych błędów (Angelidis, Degiannakis, 2006). Jak możemy zobaczyć, przedstawiona funkcja straty mierzy tylko niedoszacowanie miary ryzyka. Możemy znaleźć przypadki, gdzie pewna miara ryzyka będzie miała pożądane wartości testów dwumianowych, oraz bardzo małą wartość funkcji starty $L F$, ale jej przeszacowanie będzie bardzo duże. Dlatego też zaproponowano 
(Fałdziński, 2009), aby mierzyć również przeszacowanie miar ryzyka. Funkcja straty dla przeszacowania jest dana następująco:

$$
\begin{aligned}
\Phi_{1, t+1} & =\left\{\begin{array}{lll}
\left|E S_{t+1}-y_{t+1}\right| & \text { jeżeli } & 0<y_{t+1}<E S_{t+1} \\
0 & \text { jeżeli } & y_{t+1} \leq 0
\end{array}\right. \\
\Phi_{2, t+1} & =\left\{\begin{array}{lll}
\left(E S_{t+1}-y_{t+1}\right)^{2} & \text { jeżeli } & 0<y_{t+1}<E S_{t+1} \\
0 & \text { jeżeli } & y_{t+1} \leq 0
\end{array}\right.
\end{aligned}
$$

W tym wypadku również oblicza się średni błąd absolutny przeszacowania $M A E_{\text {over }}=\sum_{t=1}^{d} \Phi_{1, t} / d$, jak również średni błąd kwadratowy przeszacowania $M S E_{\text {over }}=\sum_{t=1}^{d} \Phi_{2, t} / d, \quad$ gdzie $d=\sum_{i=1}^{\bar{T}} \mathbf{1}, \quad \mathbf{1}=\left\{\begin{array}{lll}1 & \text { jeżeli } & 0<y_{t+1}<E S_{t+1} \\ 0 & \text { jeżeli } & y_{t+1} \leq 0\end{array}\right.$ jest

liczbą dodatnich prognoz szeregu czasowego nie większych niż dana miara ryzyka. Podobnie jak wyżej tutaj też została skonstruowana funkcja straty przeszacowania $O L F=M A E_{\text {over }}+M S E_{\text {over }}$.

\section{BADANIE EMPIRYCZNE}

Przedmiotem badania było porównanie oszacowań wartości zagrożonej i oczekiwanego niedoboru nowego podejścia z modelami zmienności. Porównanie polegało na wybraniu najlepszego modelu na podstawie funkcji strat: tej zaproponowanej przez Angelidisa i Degiannakisa (2006) $L F$, oraz funkcji strat przeszacowania $O L F$. Do symulacji wykorzystano model stochastycznej zmienności SV z rozkładem normalnym oraz model GARCH z rozkładami: normalnym i t-Studenta. Parametry szacowane były za pomocą metody największej wiarygodności $\mathrm{w}$ przypadku modeli GARCH i metody quasinajwiększej wiarygodności w przypadku modelu SV. W badaniu użyto szeregów złożonych z 3000 logarytmicznych stóp zwrotu (dane dzienne: 07.11.1994-31.10.2006), dla których szacowano 1000 wartości zagrożonych i oczekiwanych niedoborów. Do wyznaczenia ES dla modeli zmienności użyto metody zaproponowanej przez Dowda (2002). W badaniu użyto zmiennej w czasie wartości progowej $u$, która wynikała z ustalenia liczby ekstremów na poziomie $10 \%$ całego szeregu czasowego.

Na podstawie wyników badania (tabela 1 i 2) należy stwierdzić, że wyniki testu liczby przekroczeń $L R_{u c}$ i testu niezależności przekroczeń $L R_{\text {ind }} K$ są bardzo zróżnicowane i bardzo trudno jest podać ogólne wnioski. Można natomiast powiedzieć, że liczba przekroczeń $N$ jest zazwyczaj najmniejsza dla metody McNeila i Freya. Z drugiej strony najwięcej przekroczeń uzyskano dla samych modeli zmienności. Nowe podejście tutaj przedstawione cechuje się średnią ilością przekroczeń w porównaniu do dwóch pozostałych. 
Tabela 1. Wyniki testowania wstecznego dla indeksu WIG20 i SP500

\begin{tabular}{|c|c|c|c|c|c|c|c|c|}
\hline \multicolumn{9}{|c|}{ WIG20 poziom istotności 0,05} \\
\hline Model & $\mathrm{N}$ & LRuc & LRind $\mathrm{K}$. & LRind Ch, & MAE & MSE & LF & Rank LF \\
\hline GARCH & 80 & $16,15^{*}$ & $106,75^{\star}$ & 0,0633 & 0,05345 & 0,04637 & 0,09982 & 11 \\
\hline GARCH TD & 83 & $19,29^{*}$ & $106,48^{*}$ & 0,0018 & 0,08763 & 0,11428 & 0,20191 & 15 \\
\hline AR-GARCH & 74 & $10,63^{*}$ & $96,75^{\star}$ & 0,4569 & 0,04971 & 0,04303 & 0,09274 & 10 \\
\hline AR-GARCH TD & 78 & $14,20^{*}$ & $100,85^{*}$ & 0,1537 & 0,08192 & 0,10548 & 0,18740 & 14 \\
\hline SV & 47 & 0,193 & 55,70 & 1,3128 & 0,01785 & 0,01026 & 0,02811 & 3 \\
\hline GARCH-POT & 66 & $4,918^{*}$ & 78,08 & 0,1033 & 0,02968 & 0,02018 & 0,04986 & 4 \\
\hline GARCH-POT TD & 69 & $6,830^{*}$ & 81,40 & 0,0131 & 0,03115 & 0,02144 & 0,05259 & 5 \\
\hline AR-GARCH-POT & 71 & $8,260^{*}$ & 81,09 & 0,0004 & 0,04142 & 0,03207 & 0,07349 & 7 \\
\hline AR-GARCH-POT TD & 71 & $8,260^{*}$ & 78,55 & 0,0004 & 0,03183 & 0,02125 & 0,05309 & 6 \\
\hline SV-POT & 20 & $24,28^{*}$ & $48,90^{*}$ & 0,6688 & 0,00444 & 0,00249 & 0,00694 & 1 \\
\hline N-GARCH-POT & 76 & $12,36^{*}$ & 90,97 & 0,0095 & 0,04559 & 0,03676 & 0,08235 & 8 \\
\hline N-GARCH-POT TD & 80 & $16,15^{*}$ & 96,57 & 0,0310 & 0,07349 & 0,08871 & 0,16221 & 13 \\
\hline N-AR-GARCH-POT & 72 & $9,022^{*}$ & 87,70 & 0,1410 & 0,04641 & 0,03930 & 0,08572 & 9 \\
\hline N-AR-GARCH-POT TD & 75 & $11,48^{*}$ & 90,94 & 0,0278 & 0,07316 & 0,08781 & 0,16097 & 12 \\
\hline N-SV-POT & 32 & $7,776^{*}$ & 35,37 & 0,0006 & 0,01035 & 0,00589 & 0,01625 & 2 \\
\hline \multicolumn{9}{|c|}{ SP500 poziom istotności 0,05 } \\
\hline Model & $\mathrm{N}$ & LRuc & LRind $\mathrm{K}$. & LRind Ch. & MAE & MSE & LF & Rank LF \\
\hline GARCH & 45 & 0,543 & 54,73 & 0,6907 & 0,03137 & 0,02408 & 0,05545 & 11 \\
\hline GARCH TD & 51 & 0,020 & 60,56 & 0,1676 & 0,05656 & 0,06954 & 0,12610 & 15 \\
\hline AR-GARCH & 38 & 3,293 & 52,75 & 0,1650 & 0,02755 & 0,02195 & 0,04950 & 10 \\
\hline AR-GARCH TD & 40 & 2,253 & 52,27 & 0,2803 & 0,04450 & 0,05528 & 0,09979 & 14 \\
\hline SV & 36 & $4,553^{*}$ & 43,07 & 0,0792 & 0,00795 & 0,00228 & 0,01023 & 3 \\
\hline GARCH-POT & 40 & 2,253 & 53,70 & 0,2803 & 0,01320 & 0,00625 & 0,01945 & 7 \\
\hline GARCH-POT TD & 39 & 2,746 & $54,66^{*}$ & 0,2191 & 0,01296 & 0,00618 & 0,01914 & 6 \\
\hline AR-GARCH-POT & 39 & 2,746 & 50,95 & 3,1696 & 0,01295 & 0,00618 & 0,01914 & 5 \\
\hline AR-GARCH-POT TD & 37 & $3,895^{*}$ & 45,98 & 2,8468 & 0,01202 & 0,00556 & 0,01758 & 4 \\
\hline SV-POT & 10 & $49,47^{*}$ & $59,02^{*}$ & 0,2022 & 0,00131 & 0,00024 & 0,00156 & 1 \\
\hline N-GARCH-POT & 44 & 0,788 & 52,43 & 0,5951 & 0,02592 & 0,01758 & 0,04351 & 8 \\
\hline N-GARCH-POT TD & 49 & 0,021 & 51,86 & 1,1389 & 0,04273 & 0,04267 & 0,08540 & 12 \\
\hline N-AR-GARCH-POT & 38 & 3,293 & 52,75 & 0,1650 & 0,02525 & 0,01875 & 0,04401 & 9 \\
\hline N-AR-GARCH-POT TD & 39 & 2,746 & 49,60 & 0,2191 & 0,04031 & 0,04775 & 0,08806 & 13 \\
\hline N-SV-POT & 34 & $6,042^{*}$ & 42,61 & 0,0239 & 0,00760 & 0,00221 & 0,00981 & 2 \\
\hline
\end{tabular}

$N$ jest liczbą przekroczeń, tzn. kiedy stopa zwrotu jest większa od VaR. Gwiazdką (*) oznaczono wartości testów dwumianowych dla których odrzucono hipotezę zerową. N-AR-GARCH-POT w kolumnie model oznacza nową propozycję zastosowaną do modelu AR(1)-GARCH(1,1) z uwzględnieniem metody POT. TD oznacza zastosowanie rozkładu t-studenta. Odpowiednio pozostałe skróty zostały skonstruowane.

Źródło: obliczenia własne. 
Tabela 2. Wartości funkcji straty przeszacowania dla indeksu WIG20 i SP500

\begin{tabular}{|c|c|c|c|c|c|c|c|c|}
\hline \multicolumn{9}{|c|}{ WIG20 poziom istotności 0,05} \\
\hline Model & $\begin{array}{c}\text { MAEo } \\
\text { VaR }\end{array}$ & $\begin{array}{l}\text { MSEo } \\
\text { VaR }\end{array}$ & $\begin{array}{l}\text { OLF } \\
\text { VaR }\end{array}$ & MAEo ES & $\begin{array}{c}\text { MSEO } \\
\text { ES }\end{array}$ & OLF ES & $\begin{array}{l}\text { Rank } \\
\text { VaR }\end{array}$ & $\begin{array}{c}\text { Rank } \\
\text { ES }\end{array}$ \\
\hline GARCH & 1,166 & 1,622 & 2,788 & 2,167 & 5,279 & 7,446 & 3 & 7 \\
\hline GARCH TD & 1,134 & 1,545 & 2,680 & 2,610 & 7,502 & 10,111 & 1 & 14 \\
\hline AR-GARCH & 1,216 & 1,765 & 2,980 & 2,223 & 5,555 & 7,778 & 7 & 9 \\
\hline AR-GARCH TD & 1,170 & 1,642 & 2,812 & 2,661 & 7,756 & 10,416 & 4 & 15 \\
\hline SV & 1,532 & 2,888 & 4,420 & 2,118 & 5,310 & 7,428 & 13 & 6 \\
\hline GARCH-POT & 1,280 & 1,939 & 3,219 & 1,879 & 4,034 & 5,913 & 12 & 3 \\
\hline GARCH-POT TD & 1,253 & 1,862 & 3,115 & 1,846 & 3,887 & 5,733 & 9 & 2 \\
\hline AR-GARCH-POT & 1,251 & 1,867 & 3,118 & 2,061 & 4,757 & 6,817 & 10 & 4 \\
\hline AR-GARCH-POT TD & 1,249 & 1,852 & 3,101 & 1,825 & 3,810 & 5,634 & 8 & 1 \\
\hline SV-POT & 2,154 & 5,477 & 7,631 & 2,439 & 6,986 & 9,425 & 15 & 12 \\
\hline N-GARCH-POT & 1,195 & 1,714 & 2,909 & 2,072 & 4,833 & 6,905 & 5 & 5 \\
\hline N-GARCH-POT TD & 1,158 & 1,617 & 2,775 & 2,440 & 6,592 & 9,031 & 2 & 11 \\
\hline N-AR-GARCH-POT & 1,251 & 1,875 & 3,126 & 2,205 & 5,474 & 7,679 & 11 & 8 \\
\hline N-AR-GARCH-POT TD & 1,196 & 1,726 & 2,922 & 2,585 & 7,372 & 9,957 & 6 & 13 \\
\hline N-SV-POT & 1,876 & 4,609 & 6,486 & 2,308 & 6,446 & 8,754 & 14 & 10 \\
\hline \multicolumn{9}{|c|}{ SP500 poziom istotności 0,05} \\
\hline Model & $\begin{array}{l}\text { MAEo } \\
\text { VaR }\end{array}$ & $\begin{array}{l}\text { MSEo } \\
\text { VaR }\end{array}$ & $\begin{array}{l}\text { OLF } \\
\text { VaR }\end{array}$ & MAEo ES & $\begin{array}{c}\text { MSEo } \\
\text { ES }\end{array}$ & OLF ES & $\begin{array}{l}\text { Rank } \\
\text { VaR }\end{array}$ & $\begin{array}{c}\text { Rank } \\
\text { ES }\end{array}$ \\
\hline GARCH & 0,914 & 0,977 & 1,890 & 1,739 & 3,286 & 5,025 & 3 & 8 \\
\hline GARCH TD & 0,887 & 0,920 & 1,807 & 2,100 & 4,727 & 6,827 & 1 & 13 \\
\hline AR-GARCH & 0,977 & 1,103 & 2,080 & 1,817 & 3,562 & 5,379 & 11 & 11 \\
\hline AR-GARCH TD & 0,951 & 1,052 & 2,003 & 2,166 & 5,003 & 7,168 & 5 & 15 \\
\hline SV & 1,002 & 1,343 & 2,344 & 1,384 & 2,466 & 3,850 & 13 & 5 \\
\hline GARCH-POT & 0,963 & 1,075 & 2,038 & 1,364 & 2,086 & 3,450 & 7 & 1 \\
\hline GARCH-POT TD & 0,963 & 1,075 & 2,038 & 1,367 & 2,094 & 3,461 & 8 & 3 \\
\hline AR-GARCH-POT & 0,965 & 1,085 & 2,050 & 1,364 & 2,089 & 3,453 & 9 & 2 \\
\hline AR-GARCH-POT TD & 0,965 & 1,086 & 2,051 & 1,374 & 2,115 & 3,489 & 10 & 4 \\
\hline SV-POT & 1,429 & 2,619 & 4,048 & 1,650 & 3,458 & 5,108 & 15 & 9 \\
\hline N-GARCH-POT & 0,913 & 0,977 & 1,890 & 1,684 & 3,079 & 4,762 & 4 & 7 \\
\hline N-GARCH-POT TD & 0,890 & 0,931 & 1,822 & 1,990 & 4,232 & 6,222 & 2 & 12 \\
\hline N-AR-GARCH-POT & 0,977 & 1,107 & 2,084 & 1,792 & 3,453 & 5,245 & 12 & 10 \\
\hline N-AR-GARCH-POT TD & 0,951 & 1,055 & 2,006 & 2,117 & 4,757 & 6,873 & 6 & 14 \\
\hline N-SV-POT & 1,104 & 1,855 & 2,959 & 1,448 & 2,867 & 4,315 & 14 & 6 \\
\hline
\end{tabular}

MAEo VaR, MSEo VaR i OLF VaR oznaczają odpowiednio średni błąd absolutny przeszacowania dla wartości zagrożonej, średnio błąd kwadratowy przeszacowania dla VaR i funkcję straty przeszacowania dla VaR. Pozostałe oznaczenia są odpowiednie dla oczekiwanego niedoboru.

Źródło: obliczenia własne. 
Tabela 3. Ranking funkcji straty $L F$ dla indeksów

\begin{tabular}{|c|c|c|c|c|c|c|}
\hline Model & WIG & WIG20 & SP500 & DAX & FTSE100 & NIKKEI225 \\
\hline GARCH & 10 & 11 & 11 & 9 & 11 & 10 \\
\hline GARCH TD & 15 & 15 & 15 & 15 & 15 & 15 \\
\hline AR-GARCH & 11 & 10 & 10 & 8 & 8 & 11 \\
\hline AR-GARCH TD & 14 & 14 & 14 & 12 & 14 & 14 \\
\hline SV & 3 & 3 & 3 & 3 & 3 & 3 \\
\hline GARCH-POT & 6 & 4 & 7 & 5 & 4 & 7 \\
\hline GARCH-POT TD & 7 & 5 & 6 & 4 & 5 & 4 \\
\hline AR-GARCH-POT & 4 & 7 & 5 & 7 & 6 & 5 \\
\hline AR-GARCH-POT TD & 5 & 6 & 4 & 6 & 7 & 6 \\
\hline SV-POT & 1 & 1 & 1 & 1 & 1 & 1 \\
\hline N-GARCH-POT & 9 & 8 & 8 & 11 & 10 & 9 \\
\hline N-GARCH-POT TD & 13 & 13 & 12 & 14 & 12 & 13 \\
\hline N-AR-GARCH-POT & 8 & 9 & 9 & 10 & 9 & 8 \\
\hline N-AR-GARCH-POT TD & 12 & 12 & 13 & 13 & 13 & 12 \\
\hline N-SV-POT & 2 & 2 & 2 & 2 & 2 & 2 \\
\hline
\end{tabular}

Źródło: obliczenia własne.

Tabela 4. Ranking funkcji straty przeszacowania VaR dla indeksów

\begin{tabular}{|c|c|c|c|c|c|c|}
\hline Model & WIG & WIG20 & SP500 & DAX & FTSE100 & NIKKEI225 \\
\hline GARCH & 3 & 3 & 3 & 4 & 8 & 11 \\
\hline GARCH TD & 1 & 1 & 1 & 2 & 2 & 8 \\
\hline AR-GARCH & 6 & 7 & 11 & 12 & 12 & 12 \\
\hline AR-GARCH TD & 4 & 4 & 5 & 11 & 10 & 7 \\
\hline SV & 13 & 13 & 13 & 13 & 13 & 13 \\
\hline GARCH-POT & 10 & 12 & 7 & 7 & 4 & 4 \\
\hline GARCH-POT TD & 8 & 9 & 8 & 8 & 3 & 1 \\
\hline AR-GARCH-POT & 12 & 10 & 9 & 5 & 5 & 3 \\
\hline AR-GARCH-POT TD & 9 & 8 & 10 & 6 & 6 & 2 \\
\hline SV-POT & 15 & 15 & 15 & 15 & 15 & 15 \\
\hline N-GARCH-POT & 5 & 5 & 4 & 3 & 7 & 9 \\
\hline N-GARCH-POT TD & 2 & 2 & 2 & 1 & 1 & 5 \\
\hline N-AR-GARCH-POT & 11 & 11 & 12 & 10 & 11 & 10 \\
\hline N-AR-GARCH-POT TD & 7 & 6 & 6 & 9 & 9 & 6 \\
\hline N-SV-POT & 14 & 14 & 14 & 14 & 14 & 14 \\
\hline
\end{tabular}

Źródło: obliczenia własne.

W przeciwieństwie do dwóch poprzednich testów, test niezależności przekroczeń $L R_{\text {ind }} C H$ prawie zawsze wykazał nie odrzucenie hipotezy zerowej niezależnie od modelu. Porównując modele w tej samej klasie (np. SV, SV-POT 
i N-SV-POT) na podstawie funkcji straty $L F$ (tabela 3) można powiedzieć, że nowe podejście plasuje się pomiędzy metodą McNeila i Freya, a standardowymi modelami zmienności. Podobne wnioski można wydedukować na podstawie analizy funkcji straty przeszacowania $O L F$ dla oczekiwanego niedoboru (tabela 5). Oznacza to, że nowe podejście jest na tyle dobre, na ile dany model zmienności jest w stanie opisywać finansowe szeregi czasowe. Dokładniej mówiąc, im prognoza warunkowej średniej i warunkowej wariancji z modelu zmienności jest dokładniejsza tym nowe podejście jest lepsze w stosunku po dwóch pozostałych. W przypadku funkcji starty przeszacowania dla wartości zagrożonej, można zauważyć, że standardowe modele zmienności są najlepsze. To nie powinno być zaskoczeniem, ponieważ VaR lepiej dopasowuje się do małych i średnich wartości finansowych szeregów czasowych niż ES. Nowe podejście łączące modele zmienności i metodę POT tak jak poprzednio ukształtowało się pośrodku, chociaż należy nadmienić, że czasami było lepsze w porównaniu ze standardowymi modelami zmienności.

Tabela 5. Ranking funkcji straty przeszacowania ES dla indeksów

\begin{tabular}{|c|c|c|c|c|c|c|}
\hline Model & WIG & WIG20 & SP500 & DAX & FTSE100 & NIKKEI225 \\
\hline GARCH & 8 & 7 & 8 & 8 & 10 & 8 \\
\hline GARCH TD & 13 & 14 & 13 & 11 & 14 & 14 \\
\hline AR-GARCH & 9 & 9 & 11 & 9 & 11 & 9 \\
\hline AR-GARCH TD & 15 & 15 & 15 & 13 & 15 & 15 \\
\hline SV & 5 & 6 & 5 & 12 & 5 & 5 \\
\hline GARCH-POT & 3 & 3 & 1 & 4 & 2 & 4 \\
\hline GARCH-POT TD & 1 & 2 & 3 & 3 & 1 & 2 \\
\hline AR-GARCH-POT & 4 & 4 & 2 & 2 & 3 & 3 \\
\hline AR-GARCH-POT TD & 2 & 1 & 4 & 1 & 4 & 1 \\
\hline SV-POT & 10 & 12 & 9 & 15 & 7 & 11 \\
\hline N-GARCH-POT & 7 & 5 & 7 & 5 & 8 & 6 \\
\hline N-GARCH-POT TD & 12 & 11 & 12 & 7 & 12 & 13 \\
\hline N-AR-GARCH-POT & 11 & 8 & 10 & 6 & 9 & 7 \\
\hline N-AR-GARCH-POT TD & 14 & 13 & 14 & 10 & 13 & 12 \\
\hline N-SV-POT & 6 & 10 & 6 & 14 & 6 & 10 \\
\hline
\end{tabular}

Źródło: obliczenia własne.

Ogólnie można stwierdzić, że nowe podejście, które jest hybrydą standardowych modeli zmienności i metody zaproponowanej przez McNeila i Freya uwidacznia problem prognozowania stóp zwrotu finansowych szeregów czasowych za pomocą modeli GARCH i SV. Wyniki badania pokazały, że przedstawiona nowa metoda jest tak dokładna, jak dany model zmienności jest w stanie prognozować wartości w szeregu czasowym. Przedstawiono tutaj ważny problem, którym jest możliwość identyfikacji ekstremów w prognozach szeregu 
czasowego. Z pewnością ten problem nie został rozstrzygnięty, ale pokazana próba z pewnością może być wyjściem do dalszych analiz.

\section{LITERATURA}

Angelidis T., Degiannakis S. (2006), Backtesting VaR Models: An Expected Shortfall Approach, Working Papers, University of Crete, Athens University of Economics and Business

Artzner P., Delbaen F., Eber J. M., Heath D. (1997), Thinking Coherently, „Risk”, 10, 68-71

Artzner P., Delbaen F., Eber J.M., Heath D. (1999), Coherent Measures of Risk, „Mathematical Finance", 9, 203-228

Brooks, C., Clare, A.D., Dalle Molle, J.W, Persand, G. (2006), A Comparison of Extreme Value Theory Approaches for Determining Value at Risk, „Journal of Empirical Finance”, 12, 339-352

Christoffersen P.F. (1998), Evaluating Interval Forecasts, „International Economic Review”, 3,

Dowd K. (2002), Measuring Market Risk, John Wiley \& Sons Ltd., New York

Embrechts P., Klüppelberg C., Mikosch T. (2003), Modelling Extremal Events for Insurance and Finance, Springer, Berlin

Fałdziński M. (2008), Model warunkowej zmienności wartości ekstremalnych, [w:] Zielinski Z. (red.), Wspótczesne trendy w ekonometrii, Wydawnictwo Wyższej Szkoły Informatyki i Ekonomii, Olsztyn

Fałdziński M. (2009), Usefulness of the Spectral Risk Measures with Extreme Value Theory approach, Forecasting Financial Markets and Economic Decision-Making FindEcon, Łódź, submitted

Haas M. (2001), New Methods in Backtesting, Financial Engineering Research Center, Bonn

Harmantzis, F.C., Miao L., Chien Y. (2006), Empirical Study of Value-at-Risk and Expected Shortfall Models with Heavy Tails, ,Journal of Risk Finance”, 7, No.2, 117-126

Kuester, K., Mittnik, S., Paolella, M.S. (2006), Value-at-Risk Prediction: A Comparison of Alternative Strategies, „Journal of Financial Econometrics”, 4, nr 1, 53-89

McNeil J.A., Frey F. (2000), Estimation of Tail-Related Risk Measures for Heteroscedastic Financial Time Series: an Extreme Value Approach, „Journal of Empirical Finance”, 7, 271$-300$

Osińska M., Fałdziński M. (2007), Modele GARCH i SV z zastosowaniem teorii wartości ekstremalnych, $\mathrm{nr} \mathrm{X}$, [w:] Zielinski Z. (red.), Dynamiczne Modele Ekonometryczne, UMK, Toruń,

\section{EVALUATION OF THE CAPITAL MARKET RISK WITH THE APPLICA- TION OF MODIFIED POT METHOD WITH VOLATILITY MODELS}

A b s t r a c t. The main aim of this paper is presentation and empirical analysis of the new approach which combines volatility models with Peaks over Threshold method. The standard volatility models better estimate medium size values of financial times series. The new approach is based on possibility, that extremes are estimated using POT method, and medium values are estimated using standard volatility models. The contribution of this paper is analysis of the value-atrisk and the expected shortfall for this new approach. Financial risk model evaluation of this risk measures is one of the key part of this paper. Conditional tail estimates are obtained by adjusting the unconditional extreme value theory procedure with the returns filtered by standard volatility models (McNeil, Frey, 2000). Additionally, risk measures estimates obtained from volatility models with application of EVT versus those computed, using standard volatility models for financial time series are compared.

K e y w o r d s: extreme value theory, Peaks over Threshold, value-at-risk, expected shortfall 